\title{
Mycobacterium chelonae y Mycobacterium abscessus: patógenos emergentes
}

\author{
Mónica M. Ortegón'1, Gerzaín Rodríguez², Diana Camargo², Luis Carlos Orozco ${ }^{3}$
}

\begin{abstract}
Resumen
Mycobacterium chelonae es el nombre correcto para la micobacteria aislada en 1903 de los pulmones enfermos de una tortuga marina. En una especie distinta de Mycobacterium fortuitum, aislado de ranas en 1905, y de Mycobacterium abscessus, considerado actualmente como una subespecie de $M$. chelonae. Estas tres especies son las únicas patógenas para el hombre dentro del grupo de micobacterias ambientales o atípicas, de crecimiento rápido, las cuales se caracterizan por formar colonias en cultivo en menos de siete días. Son agentes etiológicos de nódulos y abscesos cutáneos, localizados y diseminados, de lesiones postoperatorias, usualmente en la cicatriz quirúrgica, de lesiones pulmonares y de linfadenitis granulomatosa, de osteomielitis y de queratitis, entre otras.

Las lesiones cutáneas y de los tejidos blandos son las más frecuentes y resultan generalmente de la inoculación traumática de esta micobacteria. Histopatológicamente, los nódulos y abscesos muestran un proceso inflamatorio, supurativo y granulomatoso, mixto, en el que en la cuarta parte de los casos pueden demostrarse conglomerados de bacilos ácido alcohol resistentes, que tienden a estar situados en una vacuola en el centro del absceso.
\end{abstract}

En Colombia, se han descrito tres brotes de abscesos subcutáneos producidos por bacterias ambientales, secundarios a la aplicación de inyecciones contaminadas con el germen causal: en 1981, en Bucaramanga, luego de la aplicación de la vacuna contra la fiebre amarilla, en 50 personas, la mayoría niños; en 1989, en Medellín, por la inyección subcutánea de alergenos, en 13 personas; y, en 1993, en varias ciudades de la costa atlántica, luego de aplicaciones subcutáneas de xilocaína, como tratamiento bionergético, en 297 pacientes. Existen otros informes aislados de casos posttraumáticos.

Laboratorio de Patología, INS, Santa Fe de Bogotá, D.C.

2 Laboratorio de Patología, INS, y Departamento de Patología, Facultad de Medicina, Universidad Nacional de Colombia, Santa Fe de Bogotá, D.C.

3 Laboratorio de Patología, INS, Santa Fe de Bogotá, D.C.; asesora en el área de investigación, Instituto PROINAPSA, Universidad Industrial de Santander, Bucaramanga.

4 Laboratorio de Patología, INS, Santa Fe de Bogotá, D.C.; profesor asistente, Escuela de Enfermería, Facultad de Salud, Universidad Industrial de Santander, Bucaramanga.

Trabajo realizado en el Laboratorio de Patología del Instituto Nacional de Salud, auspiciado por el proyecto № 32007-2. 
La enfermedad diseminada por micobacterias de rápido crecimiento, se presenta en pacientes inmunosuprimidos. En la biopsia, predominan los polimorfonucleares, no hay granuloma epitelioide y el número de bacilos es abundante.

La micobacteria implicada puede aislarse a partir de un frotis o biopsia de la lesión, pero, el diagnóstico preciso sólo puede establecerse por cultivo. Es recomendable practicar un antibiograma por las diferencias en la sensibilidad de estas micobacterias. $M$. abscessus es sensible a claritromicina, amikacina y cefoxitina. $M$. fortuitum lo es a amikacina, cefoxitina y ciprofloxacina y $M$. chelonae es sensible a cefoxitina y amikacina. El uso de monoterapia no es aconsejable.

El diagnóstico diferencial de enfermedad cutánea por micobacterias atípicas debe hacerse con todas aquellas entidades que se manifiestan por nódulos, abscesos, úlceras o trayectos fistulosos, tales como la tuberculosis, la leishmaniasis, las úlceras piógenas, los nódulos reumatoideos, los granulomas a cuerpo extraño, la esporotricosis, la nocardiosis y la botriomicosis, entre otras. Las micobacterias atípicas están entre los microorganismos que pueden producir nódulos y abscesos de propagación linfangítica. En el pulmón, el principal diagnóstico diferencial es la tuberculosis, cuando hay granulomas centrados por micrabscesos, debe pensarse en etiología por micobacterias atípicas. Estos géneros están ampliamente distribuidos en el medio ambiente. El agua y diferentes soluciones acuosas son el mayor vector para su trasmisión al hombre. Su estricta supervisión para aplicación al ser humano, el uso de agujas y jeringas desechables, la adecuada desinfección de equipos y material reutilizable con micobactericidas de comprobada eficacia, el más útil de los cuales es el glutaraldehído alcalino al $2 \%$ y el cumplimiento de unas mínimas normas de bioseguridad, son las principales medidas de control para la prevención de enfermedades producidas por micobacterias ambientales.

\section{Summary}

A mycobacterium isolated in 1903 from the lungs of a sick marine turtle was the first report of Mycobacterium chelonae. It is a different species from Mycobacterium fortuitum, isolated from frogs in 1905, and from Mycobacterium abscessus which was initially considered a subspecies of $M$. chelonae. Within the group of rapidly growing mycobacteria, which are characterized by their growth in culture in less than 7 days, these three species are the only human pathogens of the species. They are causative agents of localized or disseminated subcutaneous nodules and abscesses, of postoperative lesions, osteomielitis, queratitis and several other lesions. Skin and soft tissue lesions are most frequently observed, produced by the traumatic inoculation of these mycobacteria.

Histopathology of nodules and abscesses reveals a mixed inflammatory, supurative and granulomatous process. In one quarter of these cases, clumps of acid fast bacilli can be demonstrated, usually localized within a vacuole at the centre of an abscess.

Several outbreaks of subcutaneous abscesses produced by atypical mycobacteria, secondary to the application of contaminated injections, have been reported in Colombia. In 1981,50 people -mostly, children- were affected after vaccination against yellow fever in Bucaramanga; in 1989, 13 people were affected after subcutaneous allergen injections in Medellín. A third one involved 297 people, in 1993, along the Atlantic coast after the application of xilocayne subcutaneously for bioenergetic therapy. Other postraumatic cases have also been reported.

The disseminated disease caused by mycobacteria of rapid growth occurs in immunosuppressed patients. Polymorphonuclears predominate in skin biopsies, no epithelioid 
granuloma is observed and abundant bacilli can be demonstrated in histological sections.

The causative mycobacteria can be isolated from biopsies of lesions, since the precise diagnosis requires the accurate identification of the microrganism by culture. The practice of antibiograms is recommended due to the varying differences in antimicrobial sensitivities among these mycobacteria. M. abscessus is sensitive to clarithromycin, amikacyn and cefoxitim; $M$. fortuitum to amikacyn, cefoxitim and ciprofloxacyn, and $M$. chelonae to cefoxitim and amikacyn. Monotherapy is not recommended under any circumstances.

Differential diagnosis of cutaneous disease due to atypical mycobacteria must be made with all those clinical entities manifested by nodules, abscesses, ulcers or draining sinuses, such as tuberculosis, sporotrichosis, nocardiosis and botriomicosis. Atypical mycobacteria are among the agents which can produce skin nodules and abscesses of lymphangitic spread. In pulmonary disease, the main differential diagnosis is tuberculosis. When there are abscesses at the centre of granulomas, atypical mycobacteria etiology must be suspected.

These microorganisms are widely distributed in nature. The main source of transmission of these atypical mycobacteria to humans is via water. Strict supervision for their application to man, use of disposable syringes and needles, adequate disinfection of reusable material and equipment with proven mycobactericidals, i.e., $2 \%$ alkaline glutaraldehyde, and minimal biosecurity standards prevent diseases caused by atypical mycobacteria.

\section{Historia}

Mycobacterium chelonae fue aislado por primera vez en Alemania en 1903, por F.F. Friedman, a partir de una tortuga marina, Chelona corticata, con enfiermedad pulmonar (1). Friedman concluyó, equivocadamente, que podía utilizar este organismo al que llamó Schildkröten tuberkelbazillus o bacilo tuberculoso de la tortuga, como vacuna contra la tuberculosis, pero, al aplicarla en humanos se observó que causaba abscesos en el sitio de la inyección, motivo por el cual se abandonó su uso y su eficacia quedó desvirtuada completamente (2). En 1905, E. Kuster, también en Alemania, aisló un organismo análogo en ranas, el bacilo tuberculoso de la rana (3). Estos dos microorganismos fueron conocidos en adelante como los bacilos tuberculosos de sangre fría (cold blooded tubercle bacillus), haciendo referencia a los animales de donde provenian, y no a que los bacilos sufrieran de tuberculosis ni a que tuvieran sangre fría.
En 1920, la Sociedad Americana de Bacteriólogos estableció el uso del nombre del descubridor en la nomenclatura de las bacterias (4). Fue así como se llamó Mycobacterium friedmanii al bacilo aislado en las tortugas, nombre que no duró por mucho tiempo, porque en 1923, Bergey, en Estados Unidos, en su Manual de bacteriología determinativa (5), recomendó denominar a la bacteria con el nombre de la especie animal de donde fue aislada, en vez de utilizar el apellido del descubridor. Así surgió el nombre de Mycobacterium chelonei para este microorganismo y el de Mycobacterium ranae para la micobacteria encontrada en las ranas (5).

En 1938, da Costa Cruz, en Brasil, aisló una micobacteria a partir de un absceso cutáneo producido luego de la inyección local de vitaminas. Pensó que era una nueva especie, a la que denominó Mycobacterium fortuitum, nombre que actualmente conserva, aunque estudios posteriores demostraron que era idéntico a Mycobacterium ranae (6). 
El término de complejo $M$. fortuitum-chelonei, con el que se conoció durante algún tiempo a estas dos especies, fue introducido debido a la similitud en las condiciones que rodearon el descubrimiento de ambas especies y a ciertas características bioquímicas que comparten y que serán discutidas más adelante. Este término persistió hasta la década de los años setenta, incluso después de haberse demostrado que ambas micobacterias mostraban importantes diferencias y que debían ser consideradas especies diferentes.

Mycobacterium chelonae se ha caracterizado por tener una historia taxonómica confusa, lo cual se debe a la multiplicidad de nombres dados por distintos investigadores que han creído aislar una nueva especie, tratándose siempre de la misma micobacteria. A partir de 1953, esta especie recibió tres nombres distintos. En ese año, Moore y Frerichs en Estados Unidos, aislaron una micobacteria de un absceso glúteo en una mujer con osteoartrosis, germen que denominaron Mycobacterium abscessus (7). En 1962, Bojalil y colaboradores en Méjico, aislaron Mycobacterium runyonii a partir de un absceso cutáneo y de una muestra de esputo (8). Mycobacterium borstelense fue aislado del esputo por Bönicke, en Alemania, en 1964; el nombre se derivó del instituto donde éste trabajaba, el Forschungsinstitut Borstel (9). Y no fue sino hasta 1969 cuando los estudios realizados por Stanford y Beck en Estados Unidos, demostraron que Mycobacterium friedmanii, Mycobacterium chelonei, Mycobacterium abscessus, Mycobacterium runyonii y Mycobacterium borstelense eran casi idénticos desde el punto de vista antigénico y bioquímico, y que eran parte de una misma especie cuyo nombre correcto debía ser Mycobacterium chelonei (10). En 1972, se consideró necesaria la división de esta especie en dos grandes grupos, basándose en diferencias antigénicas, bioquímicas y de cultivo (11). Así surgen las siguientes subespecies dentro de la especie chelonei: $M$. chelonei chelonei y $M$. chelonei abscessus. Esta división fue aceptada por el Grupo Internacional de Trabajo en taxonomía micobacteriana en este mismo año (12).

En 1986, se propuso el cambio de $M$. chelonei a $M$. chelonae ya que chelonei es gramatical- mente incorrecto (13). Chelonae, en cambio, es la declinación correcta del genitivo latino de la palabra chelonae, que significa "perteneciente a la tortuga" o "de la tortuga".

Desde 1986, a partir de los estudios realizados por Lévy-Frebault y colaboradores (14) se halló que las dos subespecies, chelonae y abscessus, eran independientes porque su DNA era diferente. Estos hallazgos fueron confirmados por Kusunoki y colaboradores en 1992, quienes utilizando hibridización de DNA hallaron que las dos subespecies tenían únicamente una relación génica de $35 \%$ y que, por tanto, debían considerarse especies separadas (15).

En la actualidad, es correcto hablar de $M$. chelonae y de $M$. abscessus como especies diferentes. Las pruebas de laboratorio más frecuentemente utilizadas para diferenciar estos dos microorganismos se enuncian más adelante.

\section{Clasificación}

Han sido varios los intentos de clasificación dentro de este grupo. La clasificación inicial, y aún hoy frecuentemente utilizada, es la que divide a las micobacterias en típicas y atípicas. Surgió debido a que, desde su descubrimiento hace 100 años, los agentes causales de la lepra y la tuberculosis dominaron los estudios realizados en el género Mycobacterium; eran consideradas las micobacterias típicas. Cualquier micobacteria aislada distinta a $M$. leprae y $M$. tuberculosis era considerada como un saprófito ambiental inofensivo y por ello se agruparon dentro del epíteto de no tuberculosas, anónimas o atípicas. No fue sino hasta mediados de siglo que se conoció su verdadero potencial patógeno y creció el interés en su estudio (16).

En el grupo de las micobacterias típicas, se incluyen $M$. tuberculosis, $M$. bovis, $M$. africanum y $M$. leprae. En el grupo de las atípicas, se incluye el resto de micobacterias que actualmente comprende más de 50 especies.

En 1957, Runyon propuso la clasificación de las micobacterias atípicas en cuatro grupos, de acuerdo con el tiempo de crecimiento necesario para visualizarlas en cultivo y con la producción de pigmento $(17,18)$ (cuadro 1). 
Cuadro 1. Clasificación de Runyon de las micobacterias atípicas o ambientales *.

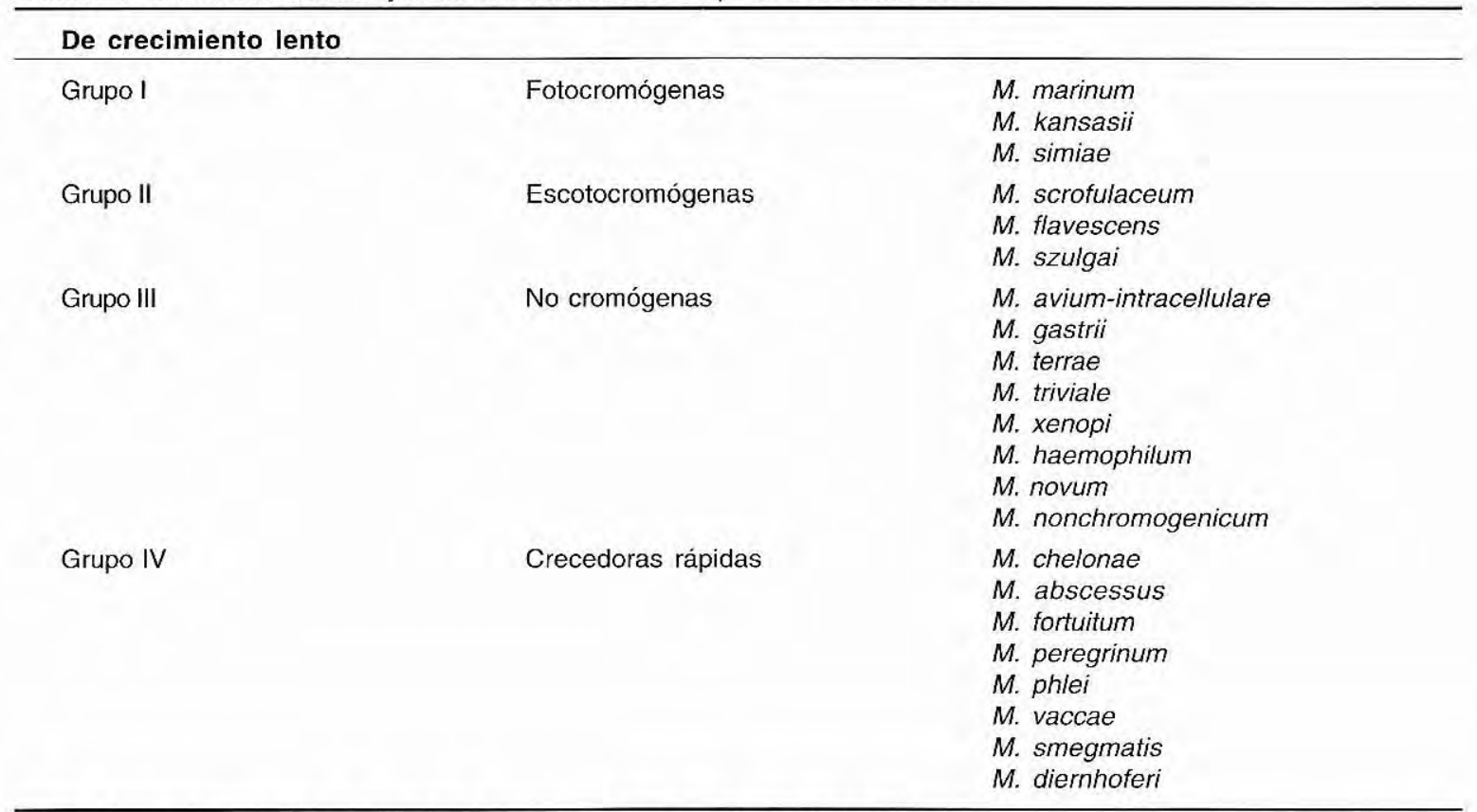

* Se incluyen algunas de las especies importantes capaces de producir patología humana.

Los tres primeros grupos están conformados por micobacterias de crecimiento lento (más de 7 días) que, además, de acuerdo con la producción de pigmento, se clasifican de la siguiente manera.

Grupo I o fotocromógenas: desarrollan un pigmento que va desde el amarillo limón hasta el rojo ladrillo cuando se exponen a la luz.

Grupo II o escotocromógenas: producen este pigmento aún en ausencia de luz.

Grupo III o no cromógenas: no producen pigmento alguno.

Grupo IV o crecedoras rápidas: se caracteriza por su crecimiento rápido, es decir, por la formación de colonias en cultivos a temperatura ambiente en menos de 7 días. Por otra parte, dentro de este grupo es posible encontrar cepas foto, escoto y no cromógenas.

Las dos clasificaciones anteriores conservan algún valor para la identificación de las micobacterias, pero la clasificación actualmente aceptada es la que divide al género Mycobacterium en dos grupos de acuerdo con su velocidad de crecimiento (19) (cuadro 2):

\section{De crecimiento lento.}

\section{De crecimiento rápido.}

Esta distinción se establece por el tiempo requerido para la formación de colonias en cultivos a temperatura ambiente; así, las de crecimiento rápido tardan menos de 7 días, a diferencia de las de crecimiento lento que pueden tardar semanas para su aislamiento en el cultivo (20).

Unicamente las especies $M$. fortuitum, $M$. chelonae y $M$. abscessus, dentro del grupo de micobacterias de crecimiento rápido, son patógenas para el ser humano.

Durante bastante tiempo se consideró a $M$. chelonae y $M$. fortuitum dentro de un mismo complejo. La separación entre las dos especies y sus subespecies fue llevada a cabo por múltiples investigadores incluyendo a Jentkins y colaboradores en 1971 (21), y Pattyn y colaboradores en 1974 (22), basándose en la composición lipídica, la seroaglutinación y en los patrones bioquímicos.

En el cuadro 3 se aprecian las pruebas de laboratorio más comunes para la diferenciación de estas dos especies y en el cuadro 4 se 
Cuadro 2. Clasificación aceptada del género Mycobacterium.

\begin{tabular}{lll} 
& De crecimiento lento & \\
\hline M. tuberculosis & M. asiaticum & M. malmoense \\
M. microti & M. szulgai & M. shimoidei \\
M. bovis & M. simiae & M. gordonae \\
M. africanum & M. scrofulaceum & M. lepraemurium \\
M. kansassii & M. avium & M. paratuberculosis \\
M. marinum & M. intracellulare & M. leprae \\
M. gastri & M. xenopi & M. triviale \\
M. non chromogenicum & M. ulcerans & M. farcinogenes \\
M. terrae & M. haemophilum & \\
\hline & De crecimiento rápido & \\
M. chelonae & $M$. gilvum & M. gadium \\
M. abscessus & M. komossense & M. pulveris \\
M. fortuitum & M. neoaurum & M. flavescens \\
M. chitae & M. obuense & M. diernhoferi \\
M. senegalense & M. parafortuitum & M. duvalii \\
M. agri & M. rhodesiae & M. chubuense \\
M. smegmatis & M. sphagni & M. austroafricanum \\
M. phlei & M. tokaiense & M. aurum \\
M. termoresistibile & M. vaccae & M. fallax \\
M. aichiense & M. porcinum & \\
\hline
\end{tabular}

Cuadro 3. Pruebas para diferenciación entre $M$. chelonae y $M$. fortuitum (biotipo A) ${ }^{\star}$.

\section{M. chelonae}

\section{M. fortuitum}

Reducción de nitratos

Crecimiento a $42^{\circ} \mathrm{C}$

Estearasa termoestable $\left(100^{\circ} \mathrm{C} / 15 \mathrm{~min}\right)$

Degradación de p-aminobenzoato

beta-D-galactosidasa

Captación de hierro

* $M$. fortuitum se divide en tres biotipos de acuerdo con la actividad sacarolítica, pero, solamente el biotipo A se ha encontrado como patógeno en humanos (25).

Cuadro 4. Pruebas para diferenciación entre $M$. chelonae y $M$. abscessus.

\begin{tabular}{lcc}
\hline & M. abscessus & M. chelonae \\
\hline Crecimiento en $\mathrm{NaCl}$ al $5 \%$ a $37^{\circ} \mathrm{C}$ & + & - \\
Crecimiento en deoxicolato al $1 \%$ & + & - \\
Crecimiento en ácido pícrico al $0,2 \%$ & + & - \\
Fosfatasa ácida termoestable $\left(70^{\circ} \mathrm{C} / 30 \mathrm{~min}\right)$ & + & - \\
$\mathrm{NO}{ }_{2}$ como fuente de nitrógeno & + & - \\
Trimetilendiamina como fuente & + & - \\
$\quad$ de carbono y nitrógeno & + & - \\
Crecimiento en agar de MacConkey a $37^{\circ} \mathrm{C}$ & + & + \\
Reacciones amidasa con alantoína & - & - \\
Citrato como fuente única de carbón & & \\
\hline
\end{tabular}


describen las pruebas de laboratorio más utilizadas para la diferenciación entre las especies chelonae y abscessus $(11,24)$.

La mayor diferencia bacteriológica que permite la identificación entre ambas especies es la reducción de nitratos. $M$. chelonae no la produce, mientras que $M$. fortuitum la produce de forma vigorosa.

\section{Bacteriología}

$M$. chelonae y $M$. abscessus son de crecimiento rápido, pero su aislamiento inicial paradójicamente, algunas veces, puede requerir varias semanas o meses de incubación (24). Las colonias de $M$. chelonae son lisas o rugosas y presentan olor a vainilla. Los cultivos frescos son no cromógenos y los antiguos desarrollan un color grisáceo. Produce una prueba de arilsulfatasa fuertemente positiva a los tres días y no crece a $45^{\circ} \mathrm{C}$ (24).

$M$. abscessus es un bacilo acido-alcohol resistente que mide $1,0-2,5 \mu \mathrm{m}$ de largo y 0,5 $\mu \mathrm{m}$ de ancho, las colonias tienen una morfología intermedia entre lisas y rugosas, presentan un color blanco o grisáceo y no son fotocromógenas. Crece a los siete días en medio de Ogawa enriquecido con huevo a $28^{\circ} \mathrm{C}$ y a $37^{\circ} \mathrm{C}$, pero no a $43^{\circ} \mathrm{C}$. La degradación de $\mathrm{p}$ aminobenzoato y salicilato es positiva (15).

Las principales diferencias entre $M$. chelonae y $M$. abscessus consisten en que este último presenta crecimiento en cloruro de sodio al $5 \%$ a $37^{\circ} \mathrm{C}$ y en presencia de ácido pícrico al $0,2 \%$ en medio de agar de Sauton, mientras que $M$. chelonae no. Además, no utiliza el citrato como fuente unica de carbón, mientras que $M$. chelonae sí lo hace (15).

\section{Enfermedad humana}

El espectro de las lesiones producidas por $M$. chelonae y $M$. abscessus va desde la formación de abscesos hasta la enfermedad diseminada y sepsis (26). Pocos casos mortales se han informado ocasionados por estos gérmenes. Se presentaron como enfermedad diseminada, asociados con patología pulmonar, sepsis por infección de heridas quirúrgicas, endocarditis de válvulas porcinas e inmunosupresión $(27,28)$. Los pacientes hemodializados son los más afectados por $M$. abscessus en el grupo de los inmunocomprometidos. La enfermedad pulmonar y la enfermedad diseminada son menos frecuentes en el espectro de enfermedad producida por $M$. chelonae.

Las siguientes son las enfermedades producidos por estas dos micobacterias:

1. Cutánea

2. Postoperatoria

3. Pulmonar

\section{Diseminada}

5.Queratitis, úlceras corneanas, linfadenitis y osteomielitis.

1. Enfermedad cutánea: es la manifestación clínica mas frecuente $(26,29)$. Su forma de presentación principal es la de abscesos localizados, en los que la infección ocurre por lesión traumática en cualquier sitio de la piel. Cirugías, accidentes de jardinería, heridas en batalla, espinas, cuchillos y alambres, han servido para inocular la micobacteria en los tejidos. También se han implicado las garras, pezuñas, púas y aguijones de algunos animales en la inoculación de estas micobacterias al hombre. En India, en 1992, se informó de la infección cutánea severa por M.chelonae secundaria a la picadura de un insecto himenóptero (30). Estos insectos transportan en sus apéndices los microorganismos que han adquirido al alimentarse de material en descomposición de origen vegetal y animal.

Cada vez son más frecuentes los casos de abscesos en los sitios de aplicación de inyecciones atribuidos al uso de jeringas o soluciones contaminadas con la micobacteria (31-33). El primer informe de la formación de un absceso en un sitio de inyección fue en 1904 y lo más probable es que el agente causal haya sido del complejo $M$. fortuitum-chelonae (34). Desde entonces, la aplicación de diversas inyecciones, incluyendo vacunas y drogas, se ha asociado con la producción de abscesos. 
Anestésicos locales, insulina, penicilina, dextranos e histamina han servido como vehículo para la inducción de las lesiones (31, 35-37).

En 1966, en Durham, Inglaterra, hubo un brote en 12 niños, que presentaron abscesos localizados en el sitio de aplicación de inyecciones de histamina, utilizadas como tratamiento para diversos tipos de rinitis y sinusitis. En tres de estos casos, se aisló $M$. abscessus (35). Otra epidemia similar ocurrió en 1969 en un centro de salud cercano a Nijmegen, Holanda, en donde se informaron 47 casos de personas con abscesos en el sitio de aplicación de la vacuna de DPT. Dichos casos se atribuyeron a $M$. chelonae (36). Otro brote ocurrió en Texas, Estados Unidos, en 1977, en donde 13 estudiantes de enfermería desarrollaron abscesos subcutáneos en la región glútea y deltoidea luego de la aplicación de inyecciones de solución salina durante una práctica que realizaban entre ellas mismas. El patógeno aislado a partir de las lesiones fue $M$. chelonae (37). En ninguno de estos brotes fue posible demostrar el origen de la infección aunque se sugiere que el organismo infectante se hallaba en las soluciones de histamina, DPT y solución salina respectivamente.

En enfermedades yatrogénicas por micobacterias ambientales son pocos los casos en los que se ha identificado la fuente de infección y se ha aislado la micobacteria desencadenante de la lesión. Dos de estos casos corresponden a dos brotes epidémicos ocurridos en diferentes hospitales de Barcelona en 1974 y 1975 , respectivamente, en donde se informaron 24 pacientes sometidos a varicectomía, luego de la cual presentaron lesiones abscedadas sobre la línea de la vena removida. La merbromina, el desinfectante cutáneo prequirúrgico utilizado, resultó ser la fuente de la infección al aislarse $M$. abscessus en el cultivo de dicha solución (38). Otra ocasión en la que pudo aislarse la micobacteria de la fuente contaminante ocurrió en 1988 en Estados Unidos, en donde 8 personas fueron hospitalizadas por lesiones en los pies causadas por $M$. abscessus, después de la realización de procedimientos invasivos con la utilización de dermoinyectores, con los cuales se realizaba la aplicación del anestésico local. Se aisló $M$. abscessus del agua destilada con la que se preparaba la solución utilizada para desinfectar los dermoinyectores (32). La otra epidemia, en la cual se identificó la fuente de infección, ocurrió en la costa atlántica colombiana y se describe más adelante (31).

Clínicamente, las lesiones que aparecen luego de la aplicación de inyecciones contaminadas se presentan como nódulos eritematosos, indoloros o abscesos, los cuales muestran drenaje espontáneo de material serosanguinolento $(31,33,36)$. Se debe sospechar enfermedad por micobacterias atípicas en aquellas lesiones inflamatorias que se desarrollan en un sitio de trauma y en las que no se evidencia curación después de la instauración de antibioticoterapia.

En Colombia, el primer informe de un caso de enfermedad cutánea por micobacterias de rápido crecimiento es el de Alvarez y colaboradores en Medellín, quienes en 1964 aislaron 23 cepas de micobacterias anónimas, una de las cuales pertenecía al grupo IV que fue la causante de lesiones perianales en un paciente de 14 años (39). En 1981, Restrepo y colaboradores, también en Medellín, informaron tres casos de lesiones en los tejidos blandos, todos con un claro antecedente traumático (40). El primero, en una paciente de 25 años de edad con fractura abierta de tibia y contaminación de las heridas con tierra. El segundo caso fue el de un hombre de 23 años quien sufrió un trauma penetrante con una astilla de madera en el pie. En estos dos casos, la micobacteria aislada fue M. fortuitum. El tecer caso ocurrió en una paciente de 21 años sometida a infiltraciones locales con corticoides, por una amiloidosis macular en su pierna izquierda. Se aisló $M$. chelonae en el cultivo. Los primeros dos casos respondieron a excisión quirúrgica y en el último se instauró antibioticoterapia que fue curativa. En 1988, Díaz, en Medellín, informó el caso de un minero de río del Chocó, quien sufrió una herida con un clavo en su pie izquierdo, 
presentando una lesión cutánea crónica nodular y ulcerada,cuyos cultivos fueron positivos para M. fortuitum (41).

Se han informado tres brotes epidémicos producidos por micobacterias ambientales en Colombia. El primero ocurrió en Bucaramanga durante los últimos meses de 1981 hasta mayo de 1982, en el centro de salud del Rosario, en donde se registraron abscesos cutáneos en cerca de 50 personas, la mayoría niños, luego de la aplicación de la vacuna contra la fiebre amarilla. Las lesiones, que se localizaban en los brazos, consistían inicialmente en pequeñas induraciones que aumentaban de tamaño hasta formar nódulos con drenaje espontáneo de material seropurulento. El período comprendido entre la aplicación de la vacuna y la aparición de las lesiones osciló entre 20 y 35 días. Algunas de las lesiones presentaron resolución espontánea, la cual dejaba como secuela notorias cicatrices. En otros casos, fue necesario practicar drenaje quirúrgico. Muestras de las lesiones de dos de los pacientes se cultivaron en el Laboratorio de Micobacterias del Insituto Nacional de Salud, aislándose $M$. chelonae subsp. abscessus. En dicho brote se descartó que los lotes de la vacuna fueran el origen de la infección, la cual probablemente se originó por contaminación de la solución salina utilizada como diluyente, aunque la confirmación de esta sospecha no se llevó a cabo en el laboartorio (Tinjacá $\mathrm{P}$, León $\mathrm{Cl}$, Giraldo E, INS, Bogotá, estudios no publicados).

El segundo brote ocurrió en Medellín entre 1988 y 1989, luego de la aplicación de inyecciones de alergenos, utilizadas como tratamiento desensibilizante en pacientes atópicos (42). Tampoco se determinó la fuente de contaminación, ni la especie de micobacteria causante de las lesiones.

El brote más reciente ocurrió entre enero y abril de 1993 (31). En este período, por lo menos, 667 pacientes procedentes de varias ciudades de la costa atlántica, principalmente de Barranquilla, Cartagena, Santa Marta, Montería y Magangué, recibieron múltiples inyecciones subcutáneas de xilocaína en la región periumbilical o glútea, como terapia llevada a cabo por un "bioenergético" para el tratamiento de diferentes dolencias orgánicas y sicosomáticas. Aproximadamente a los dos meses de iniciada la terapia, 297 pacientes desarollaron entre $1 \mathrm{y}$ 9 lesiones cutáneas que correspondían a nódulos eritemato-violáceos y abscesos que presentaban drenaje de material serosanguinolento por trayectos fistulosos, ubicados en los sitios de la aplicación de las inyecciones (figuras 1 y 2).

Se realizaron biopsias de las lesiones en 71 pacientes y se tomaron muestras para cultivo de las secreciones, de las soluciones desinfectantes y de los distintos implementos hallados en el consultorio del bioenergético. Se aisló $M$. abscessus tanto de la solución de xilocaína como de las lesiones cutáneas. A nuestro saber, ésta es la mayor epidemia yatrogénica causada por micobacterias ambientales (31).

2. Enfermedades postoperatorias: se ha descrito la infección y posterior enfermedad por micobacterias atípicas luego de los siguientes procedimientos quirúrgicos: a) esternotomía medial, practicada para realización de puentes coronarios e implantación de válvulas prostésicas; dos brotes epidémicos en Estados Unidos $(43,44)$, uno causado por $M$. chelonae y otro por $M$. fortuitum y un brote en Hungría por M. chelonae (45); b) mamoplastia de aumento, (46); c) inserción de catéter percutáneo (47); d) cirugías abdominales incluyendo laminectomía (26); e) varicectomías (38); f) dilataciones uretrales (48); y rinoplastia (49). Estas infecciones se manifiestan sobre las heridas quirúrgicas o sitios de procedimiento de dos formas: falla en el proceso de cicatrización normal o presencia de signos de infección caracterizados por drenaje de material purulento - serosanguinolento sobre la línea de sutura. Los signos y síntomas incluyen dolor, inflamación, eritema, calor y drenaje espontáneo de material purulento o serosanguinolento, los cuales en promedio se instauran a los 20 días 
postoperatorios, aunque este período ha presentado oscilaciones que van desde un mes a varios años. Generalmente, cursan sin fiebre.

3. Enfermedad pulmonar: ocurre en pacientes inmunosuprimidos o con enfermedad pulmonar subyacente, aunque también se han informado casos en pacientes previamente sanos. El $85 \%$ de las infecciones son producidas por $M$. abscessus y el restante por $M$. chelonae (50). La radiografía de tórax revela infiltrados instersticiales y alveolares, principalmente unilaterales. La observación radiológica de cavidades es también un signo distintivo, aunque no se desarrolla en todos los pacientes. Las coloraciones para bacilos ácido-alcoholresistentes a partir de muestras de lavado traqueobronquial tienen un alto grado de positividad, lo cual facilita su diagnóstico, que siempre requiere de confirmación por cultivo. Uno de los principales factores de riesgo implicados es el tabaquismo. La tomografía axial computadorizada es útil en los casos de enfermedad localizada, tanto para facilitar su ubicación en la intervención quirúrgica como para hacer el seguimiento de la evolución terapeútica. La enfermedad pulmonar también está asociada con alteraciones de la motilidad esofágica (26), artritis reumatoidea, espondilitis anquilosante y, principalmente, neumonía lipoídica (51). Esta última entidad ha despertado especial interés, pues la mayoría de las biopsias pulmonares de pacientes con enfermedad por micobacterias atípicas tienen como hallazgo constante la presencia de macrófagos cargados de lípidos. Se cree que el crecimiento de las micobacterias en las partículas de lípidos es un efecto protector contra la fagocitosis (51).

4. Enfermedad diseminada: se caracteriza por un síndrome en el que hay episodios recurrentes de abscesos de la piel y de los tejidos blandos, cuyo número oscila entre 1 y 100 , con intervalos en los que los pacientes permanecen asintomáticos. Se presenta en enfermos con alguna condición de inmunosupresión como trasplante renal, terapia con corticoides, artritis reumatoidea, linfoma o leucemia (29) (figuras 3 y 4). En la mayoría de los casos, la fuente de infección ha permanecido desconocida. El desenlace fatal de casos de enfermedad diseminada por $M$. chelonae es inusual $(52,54)$. El microorganismo puede aislarse a partir de muestras de las lesiones oo de la sangre de los pacientes con la enfermedad.

5. Infecciones misceláneas: bajo esta clasificación se incluyen las siguientes patologías infecciosas: endocarditis de válvulas prostésicas, queratitis, linfadenitis cervical (26) y osteomielitis. En el primero de los casos, los síntomas se desarrollaron aproximadamente a las doce semanas después del reemplazo valvular y se caracterizaron por fiebre, fenómenos embólicos y manifestaciones cutáneas (53). Los hemocultivos constituyen una ayuda diagnóstica definitiva, a pesar de la cual la mayoría de los pacientes fallecen, aun después de una segunda cirugía (26).

Dentro de las infecciones oculares se han informado casos de queratitis y úlceras corneales causadas por $M$. chelonae. Todas estas infecciones son secundarias a trauma 0 cuerpos extraños intracórneos $(54,55)$.

Los casos de linfadenitis ocurren principalmente en la población infantil (56). Los grupos ganglionares más afectados son los de la región superior del cuello, aunque también se ha descrito el compromiso de los ganglios pre y postauriculares y parotídeos. La enfermedad tiende a ser unilateral e indolora. Con el tiempo, los ganglios se reblandecen y presentan drenaje espontáneo, constituyendo escrofulodermas. Se piensa que el origen de la infección proviene de un foco en la cavidad oral o en las vías respiratorias superiores, aunque en pocas ocasiones se ha determinado con precisión la puerta de entrada del bacilo (55). M. chelonae es responsable de una pequeña proporción de estas infecciones (55), siendo $M$. scrofulaceum el principal agente etiológico. El tratamiento de elección es la excisión de los ganglios implicados. 


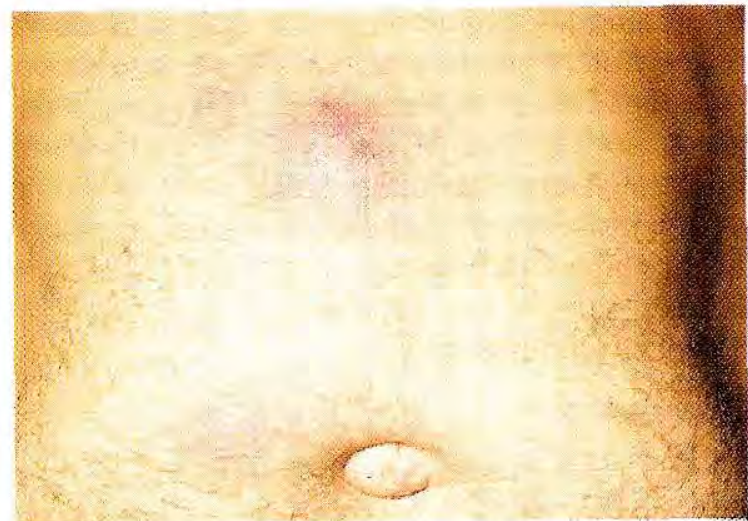

Figura 1. Nódulos para y supraumbilicales eritematovioláceos en el sitio de aplicación de inyecciones de xilocaína.

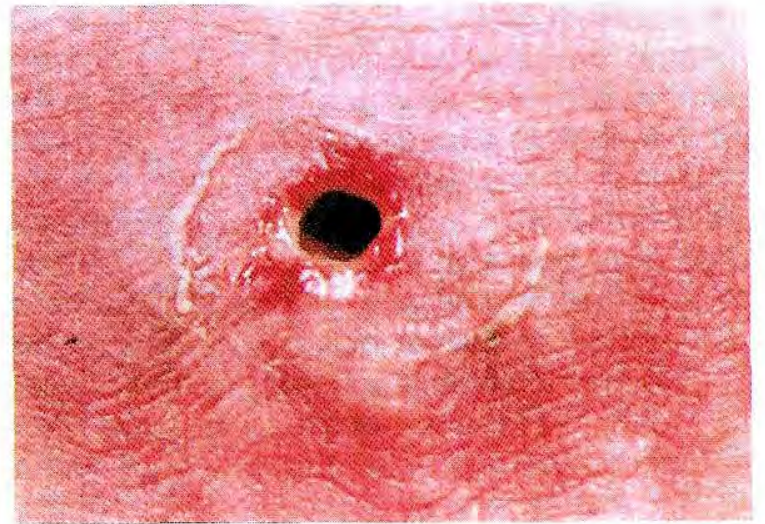

Figura 2. Fistulización de un absceso cutáneo.
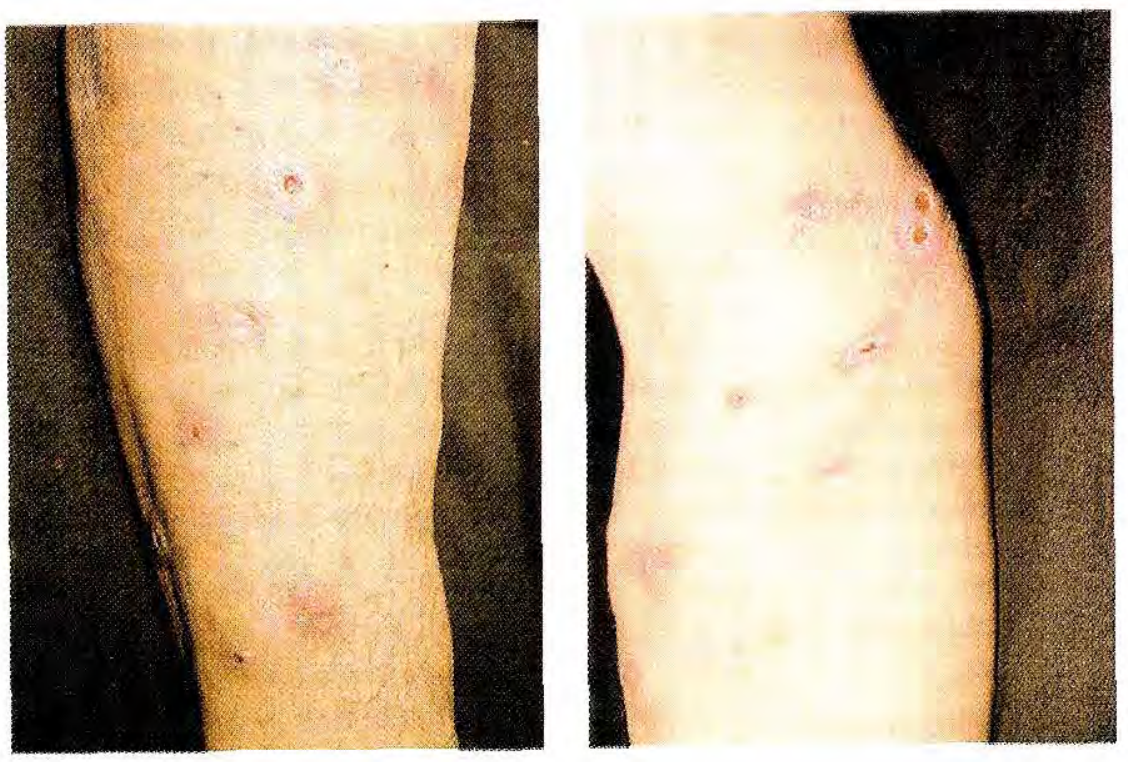

Figuras 3 y 4 . Numerosos nódulos, algunos ulcerados, en el brazo de un paciente con linfoma de Hodgkin.
La osteomielitis, con cultivos positivos para micobacterias de rápido crecimiento, se ha presentado como una complicación frecuente en casos de enfermedad cutánea por trauma penetrante. La mayoría de los casos corresponden a heridas penetrantes en los pies. Radiológicamente, se evidencia erosión ósea en el sitio de la herida y el diagnóstico de osteomielitis se confirma con el estudio histopatológico de la biopsia ósea. $M$. chelonae ha sido aislada en cultivo en la mayoría de estos casos (26).

\section{Epidemiología}

La incidencia de enfermedad causada por micobacterias atípicas ha presentado un incremento en los ultimos años. Inicialmente poco se les tenía en cuenta ya que la mayoría de estudios acerca del género Mycobacterium eran dominados por las especies tuberculosis y leprae y al resto de las micobacterias no se les consideraba importantes por creerse que no eran patógenas para el hombre. Cuando se aislaban, a partir de lesiones en animales y en humanos, se consideraba un hecho curioso e 
infrecuente. Con el tiempo creció el interés en el estudio de estos microorganismos pues se comenzaron a describir cuadros clínicos característicos producidos por éstos como el granuloma de las piscinas producido por $\mathrm{Myco}$ bacterium marinum y la úlcera de Buruli producida por Mycobacetrium ulcerans. Por tanto, el mayor conocimiento de la capacidad patogénica de las micobacterias atípicas ha creado mayor interés por su diagnóstico lo cual ha contribuido a demostrar que las enfermedades que estos gérmenes producen tienen mayor incidencia de la sospechada. Como tanto los pacientes como los médicos notan la mayor frecuencia de enfermedad producida por estos gérmenes, los consideramos patógenos emergentes.

La infección en el hombre se adquiere del medio ambiente y no hay transmisión de persona a persona. La enfermedad por $M$. chelonae y $M$. abscessus resulta de la inoculación traumática de las micobacterias en la piel o en los tejidos más profundos y de su inhalación o ingestión $(26,54)$.

Las micobacterias atípicas están ampliamente distribuidas en la naturaleza, incluyendo aguas y suelos. $M$. chelonae y $M$. abscessus pueden hallarse en el polvo doméstico, pantanos, riachuelos, fango y tuberías de agua en donde resisten la clorización. Sin embargo, se considera que el mayor vector para la transmisión de las micobacterias ambientales al hombre es el agua (56).

La naturaleza y la prevalencia de la enfermedad está determinada por tres factores (16):

1.Las condiciones que determinan la presencia de la especie y el número de micobacterias en un medio ambiente dado, tales como la temperatura, la hidratación, el $\mathrm{pH}$ y la presencia de minerales, vegetación y reservorios animales.

2.Las oportunidades para la transmisión de las micobacterias del medio ambiente al hombre.

3.La susceptibilidad de la población humana para desarrollar la enfermedad.

Las diferentes especies de micobacterias ambientales varían en su habilidad para causar enfermedad. La mayoría de las patógenas son de crecimiento lento y solamente se reconocen tres especies patógenas dentro del grupo de crecimiento rápido: $M$. chelonae, $M$. fortuitum y $M$. abscessus, las cuales originan lesiones semejantes entre sí, pero con una marcada diferencia en cuanto a sensibilidad antimicrobiana, por lo que su tipificación en cultivo es siempre deseable.

\section{Diagnóstico}

No es fácil hacer el diagnóstico de las enfermedades producidas por las micobacterias ambientales. Carecen de manifestaciones clínicas específicas por lo que no se les considera como posibles agentes etiológicos. A este punto se suma la falta de conocimiento sobre su potencial patógeno así como de sus características bacteriológicas lo que dificulta su identificación.

$M$. chelonae y $M$. abscessus pueden tener un tiempo de aislamiento primario lento lo cual hace que no se identifique el microorganismo usando los medios de cultivo rutinarios e, incluso, sucede que se diagnostica mal como un difterioide sin importancia o se descarta por no tratarse de $M$. tuberculosis (40). En contraste con la tuberculosis o la lepra, la sola presencia del microorganismo no indica que sea el agente causal. Por esto, es esencial la observación microscópica del tejido afectado ya que revela un sustrato histopatológico de la lesión, útil para la demostración de la naturaleza supurativa y granulomatosa de la enfermedad, lo cual ayuda a establecer posibles diagnósticos diferenciales.

El diagnóstico preciso sólo puede establecerse por cultivo, con aislamiento del microorganismo. Deben realizarse las pruebas bioquímicas pertinentes para la identificación exacta de la especie micobacteriana. No basta con el conocimiento del grupo al que pertenece, pues la sensibilidad antimicrobiana presenta importantes variaciones aun dentro de especies en un mismo grupo.

La identificación exacta del microorganismo también puede realizarse con métodos más complejos como la hibridización del DNA. Esta 
técnica no reemplaza al cultivo, por lo menos, en cuanto se refiere a micobacterias de crecimiento rápido.

Otro procedimiento diagnóstico con el que se cuenta es el de la respuesta a pruebas cutáneas con antígenos específicos (54). Son partículas solubles derivadas de fracciones del citoplasma del bacilo. Estas pruebas inducen una reacción cutánea pero no son sensibilizantes y son especie-específicas. Su denominación debe hacerse agregando el sufijo ina a cada especie; así, chelonina es la prueba cutánea específica para $M$. chelonae. Estas pruebas cutáneas no están disponibles en nuestro medio $y$, además, se ha visto que presentan dificultades en su interpretación, lo cual limita su uso (54).

\section{Histopatología}

Con las diferentes micobacterias se ha descrito una gama de patrones histológicos que incluyen abscesos, granulomas tuberculoides y sarcoideos, granulomas que semejan nódulos reumatoideos e inflamación crónica no específica que no sugiere lesión por micobacterias (57).

Nuestra experiencia con las lesiones de la piel por $M$. abscessus y $M$. chelonae nos hace concluir que son suficientemente severas y características como para producir o sospechar el diagnóstico, el cual siempre debe confirmarse por cultivo.

En la piel, la histopatología de las lesiones producidas por $M$. abscessus y $M$. chelonae muestra una severa respuesta inflamatoria granulomatosa nodular o difusa (figuras 5 y 6 ), con granulomas mixtos, compuestos de abscesos centrales rodeados por células gigantes y epitelioides (figuras7 a 9). A veces predominan los abscesos y hay poca inflamación granulomatosa.

Se observa una amplia penetración de los infiltrados inflamatorios al tejido celular subcutáneo (figura 10). Hay prominencia de linfocitos en las biopsias, llegando a formar en algunos casos colecciones circunscritas que semejan nodulos linfoides. La necrosis es otra característica constante, cuya localización es central, y llega a ser extensa en algunos casos, semejando la necrosis de caseificación (figura 9). Se observan diversos grados de hemorragia reciente y antigua, con la presencia de numerosos hemosiderófagos. Hay abundante fibrosis en la periferia de los granulomas (figura 8) y no es infrecuente el hallazgo de trayectos fistulosos con drenaje de material hemorrágico y supurativo. La hiperplasia epidérmica es moderada o discreta, cuando hay ulceración (58). Llama la atención la presencia de espacios claros, redondeados, vacuolares, rodeados por polimorfonucleares o células epitelioides y que se encuentran ubicados en el centro de los abscesos o dentro del área granulomatosa (5861) (figura 11). Son vacuolas lipídicas provenientes de la hipodermis que han alcanzado capas superiores por desplazamiento, debido a la severa inflamación. La importancia de estas vacuolas reside en que en ellas es más fácil la observación de los microorganismos, debido al contraste creado por la tinción rojo intensa de estos bacilos ácido-alcohol resistentes con la coloración de Ziehl-Neelsen y el fondo incoloro de estos espacios vacíos (figuras 12 y 13). Los bacilos aparecen en grupos extracelulares dentro de los microabscesos y en áreas con gran número de polimorfonucleares. Su observación está relacionada con el grado de respuesta inmune por parte del huésped y con el tipo de reacción inflamatoria. Por tanto, se pueden correlacionar aquellos casos donde la respuesta inmune es menor, caracterizada por una mayor reacción inflamatoria, gran supuración y necrosis, con un mayor número de bacilos. En los pacientes inmunosuprimidos, la respuesta inflamatoria está constituida por polimorfonucleares, no hay granuloma epitelioide y el número de bacilos es abundante (figuras 14 a 16) semejando la lepra multibacilar, la cual se puede excluir por la ausencia de compromiso neural, de bacilos intraneurales y de células espumosas o virchowcitos. Contrariamente, en aquellos casos con predominio de células epitelioides, abundantes linfocitos y escasez o ausencia de polimorfonucleares, no se demuestran histológicamente los bacilos y el diagnóstico 


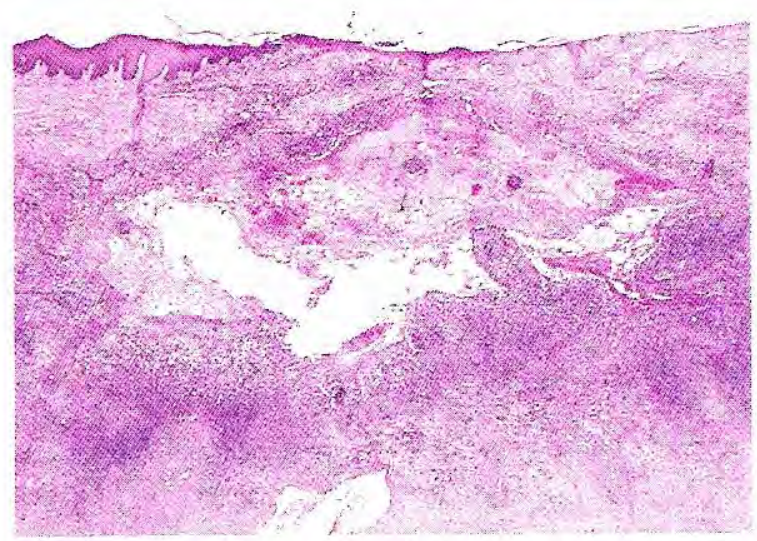

Figura 5. Absceso cutáneo por $M$. abscessus. Imagen panorámica que muestra exulceración sin hiperplasia epidérmica y dermatitis difusa muy severa, con hemorragia. El área central clara corresponde a pérdida tisular, durante el proceso de la biopsia, ocupada principalmente por PMN.

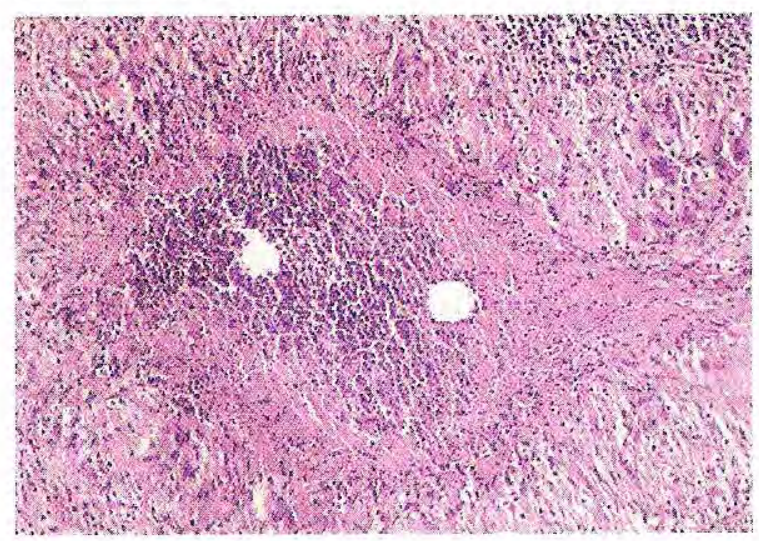

Figura 7. Granuloma mixto de células epitelioides y linfocitos que rodea un acúmulo central de neutrófilos en el cual hay dos vacuolas claras.

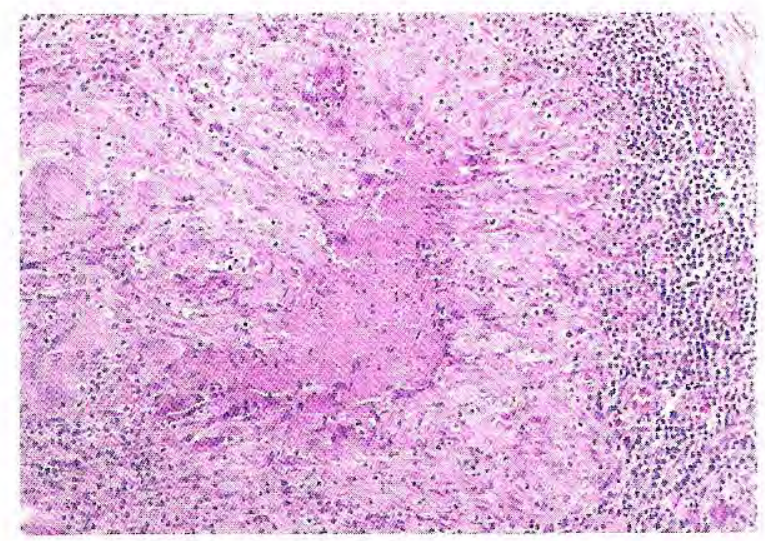

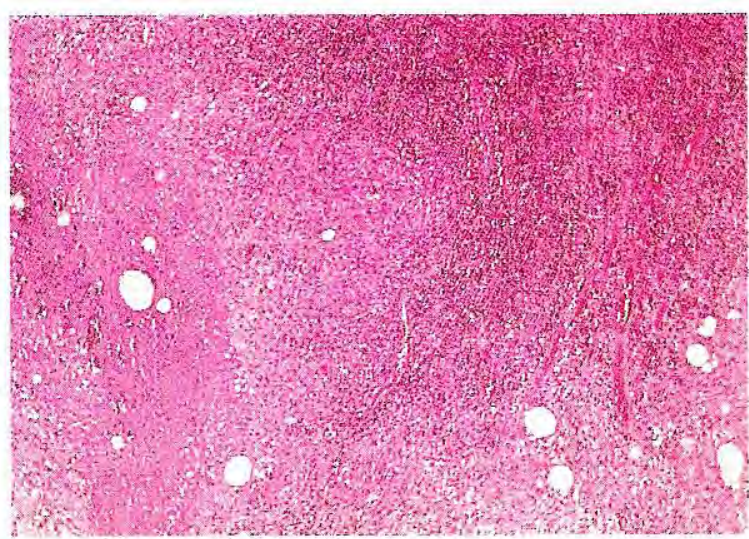

Figura 6. Imagen panorámica que muestra inflamación difusa severa de la dermis y de la hipodermis. Extensa necrosis a la izquierda. Los espacios claros son vacuolas de grasa atrapada en el proceso inflamatorio.

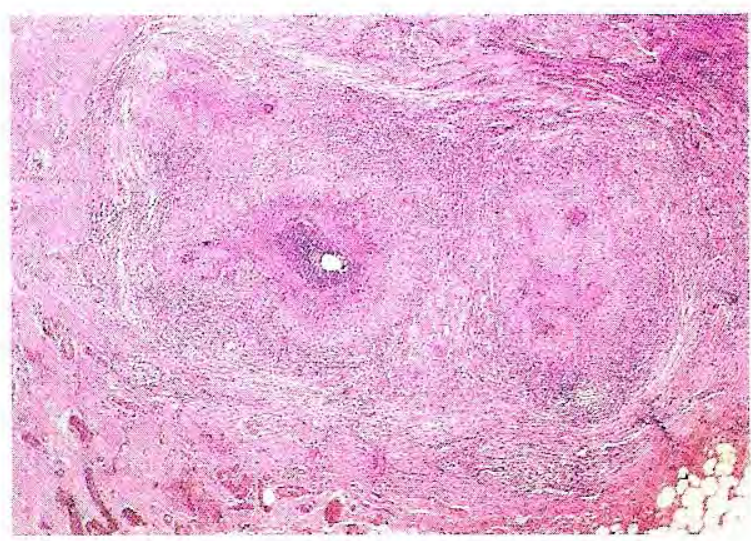

Figura 8. Granulomas confluentes consituidos por centros de PMN y material fibrinoide rodeado por células epitelioides, linfocitos y severa fibrosis. El granuloma de la izquierda tiene una vacuola central; abajo a la derecha, tejido adiposo.

Figura 9. Mayor aumento del granuloma de la derecha de la figura 8. El centro de necrosis y las células epitelioides, de Langans y linfocitos que lo rodean se demuestran con nitidez. 


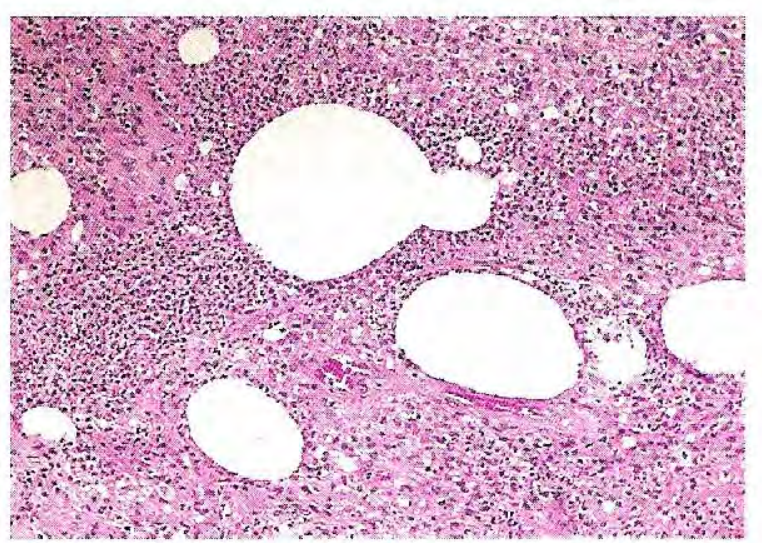

Figura 10. Vacuolas y células adiposas rodeadas por el infiltrado de neutrófilos en la unión dermohipodérmica.

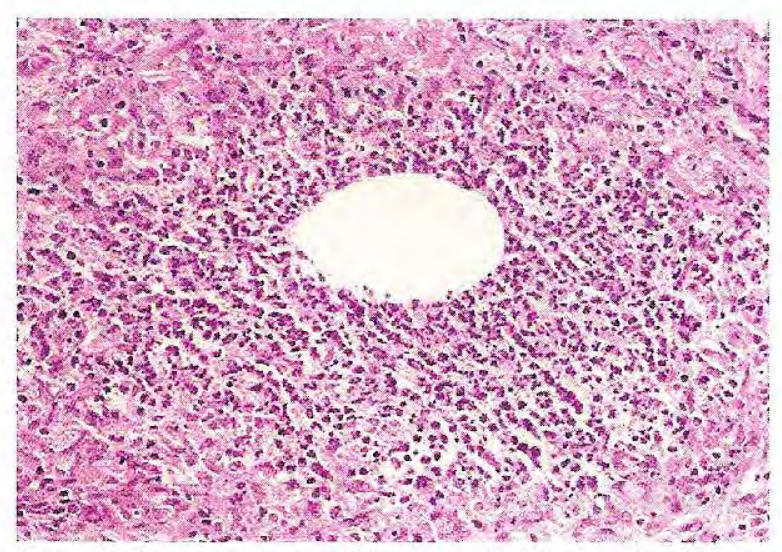

Figura 11. Vacuola, posiblemente lipídica, rodeada de neutrófilos. Estos, a su vez, están rodeados por un granuloma epitelioide; imagen típica de granuloma mixto.
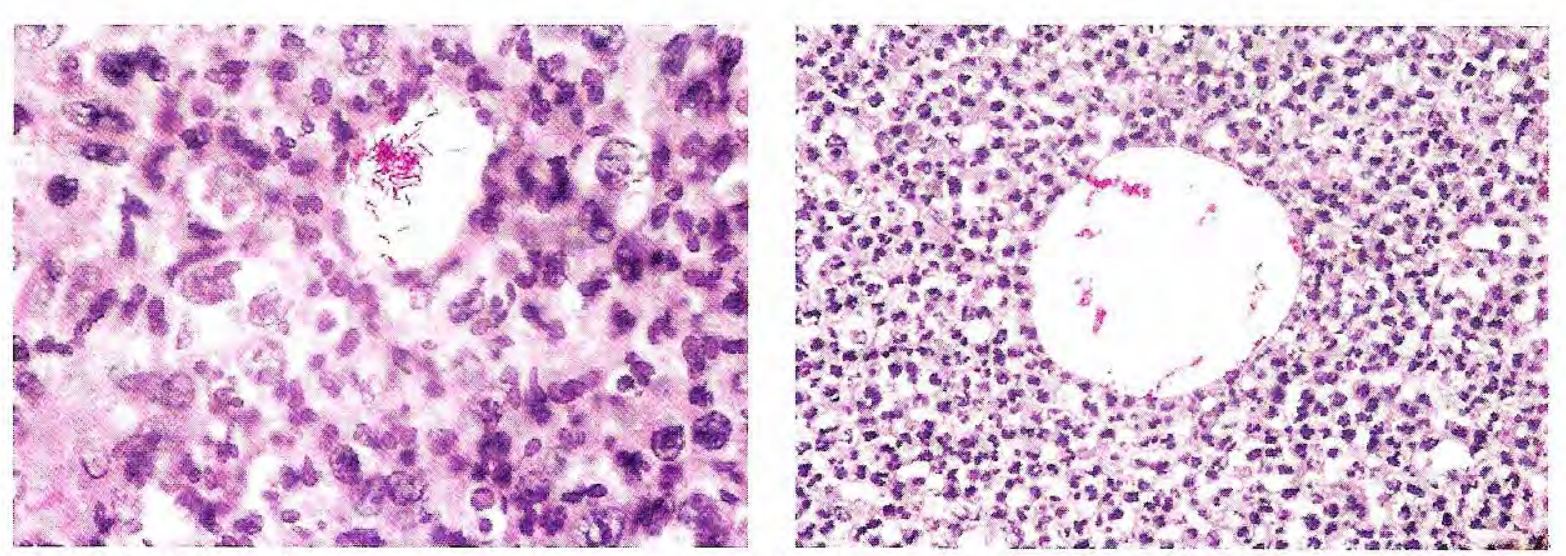

Figuras 12 y 13. Acúmulos de bacilos ácido-alcohol-resistentes en las vacuolas rodeadas por neutrófilos, cuyo cultivo fue positivo para M. abscessus (ZN 100X).
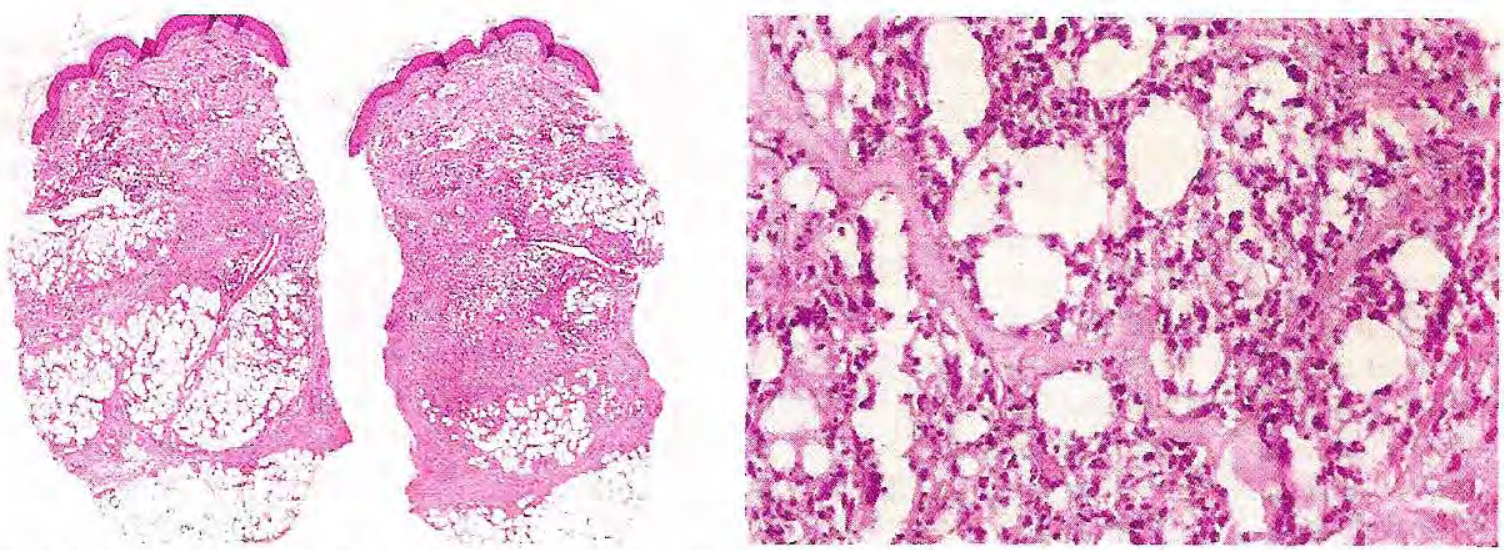

Figuras 14 y 15. Dermatitis e hipodermitis difusas neutrofílicas, en una mujer con lupus eritematoso sistémico y lesiones nodulares y ulceradas de las piernas, de las cuales se cultivó $M$. abscessus. 


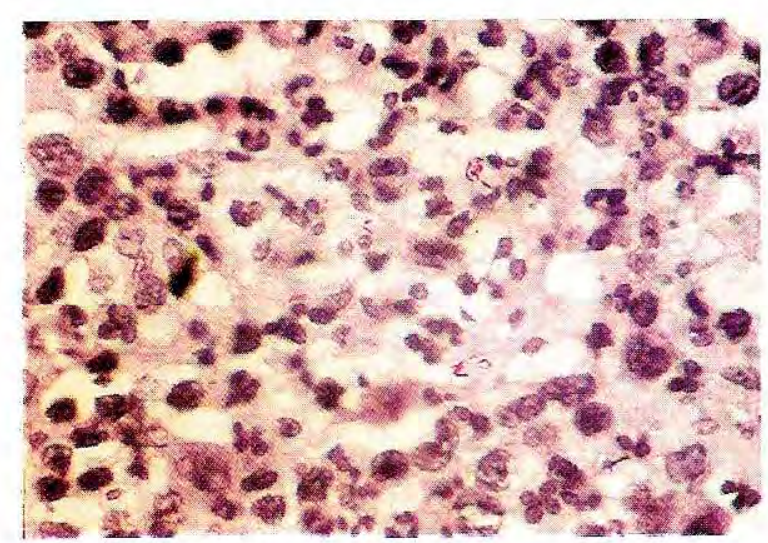

Figura 16. Abundantes bacilos ácido-alcohol-resistentes en los neutrófilos de la lesión anterior (ZN 100X).

sólo se puede confirmar por cultivo $(28,63-66)$. En el estudio histopatológico correspondiente al brote epidémico ocurrido en la costa atlántica colombiana en 1993, se detectó la presencia de bacilos ácido-alcohol resistentes en $27 \%$ de las biopsias estudiadas, principalmente en aquéllas en donde predominaban los abscesos y en aquéllas con necrosis severa. Esta positividad es alta en comparación con otros estudios (26, $58,62)$, lo cual está relacionado con el tamaño de las biopsias examinadas, con la práctica de múltiples cortes y con el tiempo dedicado al estudio de las mismas.

El examen histopatológico de la enfermedad pulmonar por $M$. fortuitum, $M$. abscessus y $M$. chelonae se caracteriza por la presencia de polimorfonucleares y microabscesos y la ausencia de necrosis de caseificación, lo cual presenta un marcado contraste con el infiltrado mononuclear y los granulomas caseificantes vistos en la tuberculosis (67). Otra diferencia importante entre la tuberculosis y las micobacterias atípicas es que en éstas la respuesta inflamatoria aguda persiste en asociación con los granulomas epitelioides y células gigantes sin importar la edad de la lesión (68). En la tuberculosis, las lesiones presentan una diferencia apreciable de acuerdo con el tiempo de evolución. Durante la fase preclínica de la enfermedad aparece un infiltrado neutrofílico; a la segunda semana se evidencia predominio de monocitos y macrófagos y a la sexta semana, cuando las lesiones originan síntomas aparecen células epitelioides y gigantes formando típicos tubérculos con granulomas y necrosis de caseificación (68).

Otra clave diferencial entre estas dos entidades está relacionada con la localización de los bacilos. Cuando están presentes en patología producida por micobacterias atípicas, se observan dentro de los microabscesos o en las vacuolas descritas (figuras 12 y 13) mientras que, en la tuberculosis, se ven en la zona de la necrosis de caseificación y en la periferia de la misma.

M. kansasii y $M$. avium-intracellulare, que son las dos especies de micobacterias atípicas que con mayor frecuencia causan enfermedad pulmonar, producen un cuadro histopatológico similar al de la tuberculosis, en tanto que las micobacterias atípicas patógenas del grupo IV tienden a producir los granulomas centrados por microabscesos ya mencionados. En las fases avanzadas de enfermedad en inmunosuprimidos, por ejemplo en SIDA, M. aviumintracelulare llena en grandes conglomerados el citoplasma de macrófagos en múltiples órganos, como el pulmón, el bazo, el hígado, el intestino y los ganglios linfáticos.

Una mayor frecuencia de endobronquitis granulomatosa con aumento en el número de células espumosas y de partículas lipídicas dentro de las células gigantes, cavidades irregulares con comunicaciones bronquiales separadas por tejido de granulación y bacilos más largos y más curvos asumiendo la forma de una $S$, son características que sugieren que las lesiones pulmonares son producidas por micobacterias atípicas (67).

Por tanto, la presencia de una respuesta inflamatoria mixta con inflamación aguda y granulomatosa, en el estudio de la biopsia pulmonar, en una lesión causada por bacilos ácido-alcohol resistentes, es eventualmente diagnóstica de infección por $M$. fortuitum, M.chelonae o M. abscessus. Siempre es necesaria la práctica de cultivos para llegar a un diagnóstico etiológico preciso. 
En conclusión, la histopatología muestra un patrón de inflamación granulomatosa, nodular o difusa, constituida por abscesos rodeados por células gigantes y epitelioides, con infiltrado periférico variable de linfocitos y plasmocitos. Hay polimorfonucleares que forman abscesos con necrosis extensa. Esta no es la típica necrosis de caseificación de la tuberculosis aunque la semeja; proviene de la desintegración tisular y del infiltrado, en gran parte como consecuencia de la destrucción de los polimorfonucleares. En inmunosuprimidos, la reacción granulomatosa puede faltar o es discreta, predominan los polimorfonucleares y abundan los bacilos.

\section{Diagnóstico diferencial}

En nuestro medio y en relación con las lesiones cutáneas por micobacterias de crecimiento rápido, la esporotricosis es el principal diagnóstico diferencial. Estas dos entidades presentan un antecedente traumático como puerta de entrada del microorganismo, en donde el hombre adquiere la infección por inoculación cutánea directa con pérdida de la integridad epidérmica debida a la penetración de objetos contaminados con los microorganismos. Múltiples objetos han sido descritos en la literatura como causantes de la infección entre los que se cuentan espinas, cuchillos, machetes, alambre de púas, palos y astillas, fragmentos de roca y vidrio, entre otros, que también son comunes para las dos enfermedades.

Las lesiones clínicas de la esporotricosis en sus estadios iniciales pueden ser muy similares a las de micobacterias atípicas. Se manifiesta como un nódulo o úlcera confinado al sitio de inoculación del hongo en el caso de la forma fija de la enfermedad. La forma linfangítica, caracterizada por un nódulo ulcerativo en el sitio de inoculación, con posterior aparición de nódulos en cadena siguiendo el trayecto de vasos linfáticos, también ha sido descrita en lesiones cutáneas producidas por $M$. chlelonae $(63,69)$. Cuando hay propagación linfangítica de las lesiones, debe pensarse en esporotricosis, leishmaniasis, nocardiosis y enfermedad por micobacterias atípicas.
La histopatología de lesiones cutáneas de esporotricosis no muestra la cantidad de acúmulos de linfocitos, ni la hemorragia con presencia de siderófagos, ni la reacción epitelioide tan prominente y organizada que se observa en las lesiones por micobacterias atípicas de rápido crecimiento. Se observa una hiperplasia epidérmica pseudocarcinomatosa severa, que no se ve en lesiones por micobacterias atípicas. Otra diferencia importante la constituye el cuerpo asteroide esporotricósico, el cual es una clave diagnóstica típica de la entidad. Está compuesto por una levadura central gemante, rodeada por espículas eosinofílicas, que reacciona inmunohistoquímicamente con un anticuerpo anti-Sporotrix schenkii, lo cual demuestra que el cuepo asteroide esporotricósico es un signo específico de la enfermedad, distinto al cuerpo asteroide intracelular de otras entidades granulomatosas (70). Lo anterior, más el cultivo del hongo, son métodos eficaces de gran ayuda en la diferenciación entre lesiones producidas por micobacterias atípicas y la esporotricosis.

El diagnóstico histológico diferencial de micobacteriosis cutáneas atípicas es extenso. Una gran diversidad de entidades granulomatosas como sarcoidosis, reacciones a cuerpo extraño, rosácea granulomatosa, eritema indurado, necrobiosis lipoídica, nódulos reumatoideos, inflamación granulomatosa por parásitos, lepra tuberculoide y tuberculosis, pueden semejar lesiones producidas por micobacterias atípicas.

Otro diagnóstico diferencial que debe considerarse es el de botriomicosis, en donde se presentan granulos basófílicos característicos que corresponden a colonias bacterianas situadas en el centro de abscesos cutáneos. En esta entidad, el componente granulomatoso no es tan severo.

\section{Tratamiento}

El tratamiento de las enfermedades producidas por micobacterias atípicas consiste en la debridación y resección quirúrgica del área afectada, si la infección es localizada, y en el uso de quimioterapia en los restantes tipos de enfermedades. 
La excisión quirúrgica o el drenaje en caso de infección localizada han mostrado ser más curativos que la quimioterapia (54). En 10 a $20 \%$ de las lesiones cutáneas, se ha visto la regresión espontánea, pero esto puede tardar ocho meses en promedio (55). En determinadas circunstancias, se hace necesario practicar una resección amplia que puede llevar a condiciones desfigurantes, que requieren la realización de injertos cutáneos.

El tratamiento quimioterápico es complicado por la susceptibilidad limitada de las micobacterias a los antimicrobianos, lo cual a su vez varía entre las diferentes micobacterias de un mismo grupo e incluso entre cepas dentro de una misma especie.

Antes de 1978, se administraban las drogas antituberculosas tradicionales en el tratamiento de enfermedades por micobacterias atípicas. No resulta sorprendente que estos regímenes terapéuticos hayan resultado inefectivos dada la resistencia in vitro de los microorganismos a estas drogas, hecho que fue demostrado posteriormente.

En la actualidad, se conocen los siguientes perfiles de sensibilidad para las micobacterias patógenas del grupo IV $(29,50,71,72)$ : $M$. abscessus es sensible a amikacina, cefoxitina y claritromicina. $M$ fortuitum es sensible a amikacina, cefoxitina, ciprofloxacina, sulfonamidas e imipenems. $M$. chelonae, en general, muestra más resistencia a los antimicrobianos que las otras micobacterias de su grupo. In vitro es susceptible a amikacina y cefoxitina y, ocasionalmente, es sensible a eritromicina y doxiciclina.

En las últimas dos décadas, se han utilizados múltiples esquemas terapéuticos para la enfermedad por micobacterias de crecimiento rápido. Se ha utilizado eritromicina, sulfonamidas, aminoglucósidos, doxiciclina, cefoxitina $y$, recientemente, quinolonas e imipenems. Los resultados obtenidos presentan una gran variabilidad $y$ en el momento no hay un esquema único y satisfactorio. La única regla terapéutica de la que se dipone es la utilización de terapias combinadas debido al extenso desarrollo de resistencia a múltipies drogas empleadas como monoterapia.

Cuando se sospeche una infección por micobacterias de crecimiento rápido, se recomienda la asociación de amikacina y cefoxitina hasta que se realize la identificación de la especie y se hagan los correspondientes perfiles de sensibilidad (50). El mayor inconveniente con el uso de aminoglucósidos como la amikacina es el conocido potencial nefrotóxico y ototóxico de la droga.

La claritromicina, uno de los últimos macrólidos orales, ha demostrado su efectividad y seguridad en el tratamiento de enfermedad cutánea diseminada por $M$. chelonae (73). La dosis utlizada de $500 \mathrm{mg}$, dos veces al día, por 6 semanas, llevó a la curación de las lesiones cutáneas, sin presencia de recaídas en un período de seguimiento de 6 meses.

En pacientes con enfermedad pulmonar por $M$. chelonae y $M$. abscessus, se han utilizado múltiples agentes antimicrobianos con resultados clínicos variables. Dentro de las terapias de mayor uso, se incluyen antimicrobianos como amikacina, cefoxitina, eritromicina y ciprofloxacina, como monoterapia o terapia combinada. No hay un régimen terapéutico establecido que haya mostrado ser efectivo en el tratamiento de enfermedad pulmonar por estas dos micobacterias (50). Algunos autores se inclinan por un abordaje conservador de la entidad, dada la presentación poco sintomática y de progreso indoloro y por la ausencia de drogas con efectividad demostrada (74). En el futuro se espera la aparición de nuevos agentes quimioterápicos con menor toxicidad y mayor eficacia.

\section{Prevención}

Cualquier evento que implique la alteración en la integridad de la piel es un factor de riesgo para la presencia de enfermedad. Es imprescindible disminuir y, en lo posible, evitar los accidentes traumáticos con diversos elementos que han servido como vehículos para la inoculación de las micobacterias, principalmente en ciertas ocupaciones que exigen la manipulación de elementos de la naturaleza, como la jardinería, 
la floricultura, la pesca y, en general, cualquier actividad que se desarrolle en estrecho contacto con ésta. En estos casos, es esencial la utilización de los elementos de seguridad adecuados, como son el uso de guantes, overoles, cascos, gafas y demás utensilios protectores fabricados con material resistente.

En brotes epidémicos relacionados con la aplicación de inyecciones, los factores de riesgo implicados son dos: el uso de jeringas, dermoinyectores y material reutilizable (endoscopios (75), instrumental odontológico) contaminado y la inoculación accidental directa de una suspensión de microorganismos contenida en las soluciones utilizadas para la aplicación en tejidos humanos. En el primer caso, la contaminación se debe a una asepsia y antisepsia inadecuada del material. Los antisépticos de uso común como el hipoclorito de sodio, los cuales se utilizan para la desinfección del material, tienen una baja acción micobactericida, permitiendo el crecimiento de estos microorganismos y perpetuando su transmisión a varios pacientes. El desinfectante de elección y al cual no presentan resistencia la mayoría de las micobacterias ambientales es el glutaraldehído alcalino al $2 \%$ (2\% glutaraldehído alcalino neutralizado a un $\mathrm{pH}$ de 8,0 , según recomendaciones del productor) (76). Su nombre comercial es CIDEX (Johnson \& Johnson). Todos los instrumentos de uso repetido y que impliquen su contacto con la piel o las secreciones de un paciente, deben ser colocados en cantidad suficiente de este líquido durante, por lo menos, 30 minutos antes de su utilización.

La medida preventiva principal debe ser la de evitar el empleo de material reutilizable. La Organización Mundial de la Salud se ha pronunciado en este sentido y restringe el uso de material no desechable únicamente a situaciones especiales, debido a la elevada frecuencia de transmisión de enfermedades infecciosas (HIV, hepatitis B y micobacterias ambientales, entre otras).

La contaminación de soluciones acuosas, mantenidas durante largo tiempo, se debe a que el agua es el mayor vector para la transmisión de micobacterias ambientales al hombre y tales soluciones son un microambiente ideal para su reproducción. Por esta razón, se recomienda mantenerlas bajo extricta supervisión. Deben conservarse en el envase original, el cual debe ser desechado una vez se haya efectuado la extracción completa del líquido, sin volver a remplazar la solución para evitar el paso de contaminantes de un recipiente a otro. La extracción del líquido de un mismo envase, como frecuentemente ocurre en el caso de anestésicos locales intradérmicos, debe efectuarse únicamente con material estéril (jeringas estériles desechables), las cuales deben desecharse una vez se hayan utilizado sin guardarse para posteriores extracciones, ni mucho menos deben permanecer incluidas en los tapones o corchos de caucho de los frascos, ya que se constituiría en una puerta de entrada de microorganismos del medio ambiente a la solución. Además, se recomienda la esterilización periódica en autoclave de toda solución acuosa mantenida durante períodos largos de tiempo.

La puesta en práctica de estas sencillas medidas de bioseguridad contribuyen al control de enfermedades por micobacterias ambientales y de otros agentes patógenos.

\section{Agradecimientos}

A la doctora Esperanza Meléndez por las ilustraciones de las figuras 1 y 2 y al doctor Alvaro Acosta por las de las figuras 3 y 4 .

\section{Referencias}

1. Friedmann FF. Der Schildkröten tuberkelbazillus, seine Zuchtung, Biologie und Pathogenitat. Zentralblat fur Bakteriologie, Parasitenkunde, Infectionskrankheiten und Hygiene, I. Orig. 1903;34:647-793.

2. Fowler WC. A preliminary report on the treatment of tuberculosis with turtle vaccine. Tubercle 1930;12:12.

3. Kuster E. Über Kaltbluttuberculose. Münchener Medizinische Wochenscrift 1905;52:57.

4. Holland D. Final report of the Committee of the Society of American Bacteriologists on characterization and classification of bacterial types. J Bacteriol 1920; 5:224. 
5 Bergey DH, Harrison FC, Breed RS, et al. Bergey's Manual of determinative bacteriology, 1st. edition. Baltimore: Williams and Wilkins Co.; 1923.

6. Da Costa J. Mycobacterium fortuitum: un novo bacilo acido resistente patogenico para o homen. Acta Med Rio Janeiro 1938;1:297.

7. Moore M, Frerichs JB. An unusual infection of the knee with subcutaneous abscess-like lesions of the gluteal region. J Invest Dermatol 1953;20:133.

8. Bojalil LF, Cerbón J, Trujillo A. Adansonian classification of mycobacteria. J Gen Microbiol 1962;28:333.

9. Bönicke R. Beschreibung der neuen Species M borstelense n.sp. Zentralblatt fur Bakteriologie, Parasitenkunde, Infectionskrankheiten und Hygiene, I. Orig. 1964;130:149.

10. Stanford JL, Beck A. Bacteriological and serological studies of fast growing mycobacteria identified as $M y$ cobacterium friedmanii. J Gen Microbiol 1969;58:99.

11. Stanford JL, Pattyn SR, Gunthorpe WJ, et al. Studies on Mycobacterium chelonei. J Med Microbiol 1972;5:171-82

12. Kubica GP, Baess IY, Gordon RE, et al. A cooperative numerical analysis of rapidly growing mycobacteria. J Gen Microbiol 1972;72:55.

13. Bergey DH. Bergey's manual of systematic bacteriology. In: Sneath PHA, Mair NS, Sharpe ME, Hott JG, eds. Based on Bergey's manual of determinative bacteriology. Vol 2, section 16. Baltimore: Williams and Wilkins; 1989.

14. Lévy-Frébault V, Grimont F, Grimont PAD, et al. Deoxyribonucleic acid relatedness study of the $\mathrm{MyCO}-$ bacterium fortuitum-Mycobacterium chelonae complex. Int J Syst Bacteriol 1986;36:458-60.

15. Kusunoki S, Ezaki T. Proposal of Mycobacterium peregrinum sp. nov., nom. rev., and elevation of $\mathrm{Myco}$ bacterium chelonae subsp. abscessus (Kubica et al.) to species status: Mycobacterium abscessus comb. nov. Int J Syst Bacteriol 1992;41:240-5.

16. Grange JM. Infection and disease due to the environmental mycobacteria. Trans Roy Soc Trop Med Hyg $1987 ; 81: 178-82$

17. Runyon EH. Anonymous mycobacteria in pulmonary disease. Med Clin North Am 1959;43:273-8.

18. Vestal AL. Procedures for the isolation and identification of mycobacteria. Atlanta: U.S. Printing office, Dept. of HEW, Publication №79-8230; 1978.

19. Lapage SP, Sneath PHA, Lessel VDB, et al. International code of nomenclature of bacteria. Revision. Washington, D.C.: American Society for Microbiology; 1979.

20. Lévy-Frébault V, Portaels F. Proposed minimal standards for the genus Mycobacterium and for description of new slowly growing Mycobacterium species. Int J Syst Bacteriol 1992;42(2):315-23.

21. Jenkins PA, Marks J, Schaefer WB. Lipid chromatography and seroagglutination in the classification of rapidly growing mycobacteria. Am Rev Res Dis 1971;103:179-87.
22. Pattyn SR, Magnusson M, Stanford JL, Grange JM. A study of Mycobacterium fortuitum (ranae). J Med Microbiol 1974;7:67-76.

23. Grange JM. A fluorigenic substrate for the rapid differentiation of Mycobacterium fortuitum from $\mathrm{MyCO}$ bacterium chelonei on the basis of heat-stable esterase activity. Tubercle 1977;58:147.

24. Grange JM. Mycobacterium chelonei. Tubercle $1981 ; 62: 273-6$

25. Bönicke R. The ocurrence of atypical mycobacteria in the environment of man and animal. Bulletin of International Union Against Tuberculosis 1966;37:361.

26. Wallace RJ Jr., Swenson JM, Silcox VA, et al. Spectrum of disease due to rapidly growing mycobacteria. Rev Infect Dis 1983:5:657-79.

27. Paul J, Baigrie C, Parums DV. Fatal case of disseminated infection with the turtle bacillus Mycobacterium chelonae. J Clin Pathol 1992;45:528-30.

28. Pottage JC Jr., Harris AA, Trenholme GM, et al. Disseminated Mycobacterium chelonei infection: a re port of two cases. Am Rev Respir Dis 1982;126:720-2.

29. Wallace RJ, Brown BA, Onyi GO. Skin, soft tissue and bone infections due to Mycobacterium chelonae: importance of prior corticosteroid therapy, frequency of disseminated infections and resistance to oral antimicrobials other than clarithromycin. J Infect Dis 1992;166:405-12.

30. Singh S, Rattan A, Kumar S. Severe cutaneous Mycobacterium chelonei infection following a yellow jacket sting. Tuber Lung Dis 1992;73:305-309.

31. Camargo D, Saad C, Ruiz F, et al. latrogenic outbreak of Mycobacterium chelonae skin abscesses. Epidemiol Infect 1996;117:113-9.

32. Wenger JD, Spika JS, Smithwick RW et al. Outbreak of Mycobacterium chelonae infection associated with the use of jet injectors. JAMA 1990;264: 373-6.

33. Jackson PG, Keen H, Noble CJ, Simmons NA. In jection abscesses due to Mycobacterium chelonel occuring in a diabetic patient. Tubercle 1981;62:277-9.

34. Ophüls, W. Chronic subcutaneous abscess in man containing acid-proof bacilli in pure culture. J Med Res $1904 ; 11: 439$

35. Inman PM, Beck A, Brown AE et al. Outbreak of injection abscesses due to Mycobacterium abscessus. Arch Dermatol 1969;100:141-7.

36. Borghans JGA, Stanford JL. Mycobacterium chelonei in abscess after injection of diphteriaperfussis-tetanus-polio vaccine. Am Rev Respir Dis 1973:107:1-8.

37. Gremillion DH, Mursh SB, Lerner CJ, Injection site abscesses caused by Mycobacterium chelonae. Infect Control 1983;4(1):25-8. 
38. Foz A, Roy C, Jurado J, et al. Mycobacterium chelonei iatrogenic infections. J Clin Microbiol 1978;7:319-21.

39. Alvarez GR, Gallego H, Montes M, et al. Aspectos bacteriológicos en el estudio de la tuberculosis. Antioquia Médica 1966;16:781-2.

40. Restrepo A, Jiménez B, Cano I, et al. Lesiones de los tejidos blandos causadas por Mycobacterium fortuitum-chelonei. Acta Med Colomb 1981;6(2):23540.

41. Díaz J. Lesión cutánea por micobacteria atípica. Medicina UPB 1988;7(1):27-31.

42. Estrada S, Díaz J, Jaramillo E, et al. Un brote por Mycobacterium chelonae subespecie abscessus, asociado a hiposensibilización en pacientes alérgicos. Acta Med Colomb 1992;17:72-6.

43. Hines MP, Waggoner R, Vernon TM. Atypical mycobacterial wound infections, North Carolina, Colorado. MMWR 1976;25:238.

44. Hoffman PC, Fraser DW, Robicsek F, et al. Two outbreaks of sternal wound infections due to organisms of the Mycobacterium fortuitum complex. J Infect Dis 1981;143:533-42.

45. Szabó Y, Sárkösi K. Mycobacterium chelonei endemy after heart surgery with fatal consequences. Am Rev Respir Dis 1979;120:197-201.

46. Clegg HW, Foster MT, Sander WE Jr, et al. Infection due to organisms of the Mycobacterium fortuitum complex after augmentation mammoplasty: clinical and epidemiologic features. J Infect Dis 1983;147:427-33.

47. Band JD, Ward JI, Fraser DW, et al. Peritonitis due to a Mycobacterium chelonei-like organism associated with intermittent chronic peritoneal dialisis. J Infect Dis 1982;145:9-17.

48. Zina AM, Depaoli M, Bossano AF. Cutaneous mucous infection with lymphadenopathy caused by $M y$ cobacterium chelonei. Dermatologica 1980;160:376-9.

49. Soto LE, Bobadilla ME, Villalobos $Y$, et al. Post-surgical nasal celulitis outbreak due to $M$. chelonae. J Hosp Infect 1991;19:99-106.

50. Singh N, Yu VL. Succesful treatment of pulmonary infection due to Mycobacterium chelonae: case report and review. Clin Inf Dis 1992;14:156-61.

51. Greenberg PA, Katzteinstein AL. Lipid pneumonia with atypical mycobacterial colonization. Arch Intern Med 1983;143:2003-5.

52. Paul J, Baigrie C, Parums DV. Fatal case of disseminated infection with the turtle bacillus Mycobacterium chelonae. J Clin Pathol 1992;45:528-30.

53. Lawskoski LF, Marr JJ, Spernoga JF, et al. Fastidious mycobacteria grown from porcine prosthetic heart valve cultures. N Engl J Med 1977;297:101.
54. Wallace RJ Jr., Jones DB, Wiss K, et al. Sulfonamide activity against $M y c o b a c t e r i u m$ fortuitum and $M y$ cobacterium chelonei. Rev Inf Dis 1981;3:898-904.

55. Wolinsky E. Nontuberculous mycobacteria and associated disease. Am Rev Resp Dis 1979;119:107-59.

56. Morris CA, Grant GH, Everall PH, et al. Tuberculoid lymphadenitis due to Mycobacterium chelonei. J Clin Pathol 1973;26:432.

57. Goslee S, Wolinsky E. Water as a source of potentially pathogenic mycobacteria. Am Rev Resp Dis 1976;113:287-92.

58. Santacruz DJ, Strayer DS. The histologic spectrum of the cutaneous mycobacterioses. Hum Pathol 1982;13:485-95.

59. Rodríguez G, Ortegón M, Camargo D, Orozco LC. Histopathology of nodules and abscesses produced by Mycobacterium abscessus. A study of 71 patients. Br J Dermatol (aceptado para pulicación).

60. Fitzgerald DA, Smith AG, Lees A, et al. Cutaneous infection with Mycobacterium abscessus. $\mathrm{Br} J$ Dermatol 1995;132:800-4.

61. Oñate JM, Mader J, Vanaclocha F, et al. An unusual form of Mycobacterium chelonei infection. Am J Dermatopathol 1986;8:73-8.

62. Kwok-wah C, Ling JML, Mak KH. Purulent mycobacterial granuloma. Am J Surg Pathol 1984;8:635-7.

63. Chester A, Winn WC Jr. Unusual and newly recognized patterns of nontuberculous mycobacterial infection with emphasis on the inmunocompromised host. Pathol Annu 1986;1:251-70.

64. Higgins EM, Lawrence CM. Sporotrichoid spread of Mycobacterium chelonei. Clin Exp Dermatol 1988;13: 234-6.

65. Collins RJ, Chow SP, Ip IK et al. Sinovial involvement by Mycobacterium marinum. A histopathological study of 25 culture proven cases. Pathol 1988;20:340345.

66. Hendrick SJ, Jarizzo JL, Newton RC. Giant Mycobacterium fortuitum abscess associated with systemic lupus erythematosus. Arch Derm 1986;122:695-7.

67. Snijder J. Histopathology of pulmonary lesions caused by atypical mycobacteria. J Pathol Bact 1965; $90: 65-73$.

68. Merckx JJ, Soule EH, Karlson AG. The histopathology of lesions caused by infections with unclassified acid fast bacteria in man. Am J Clin Pathol 1964;41:244-55.

69. Greer KE, Gross GP, Martensen SH. Sporotrichoid cutaneous infection due to Mycobacterium chelonei. Arch Dermatol 1979;115:738-39.

70. Rodríguez G, Hernández CA. Leishmaniasis vs. esporotricosis y otros diagnósticos diferenciales de la 
leishmaniasis tegumentaria. Rev Soc Col Dermatol 1992;1:186-98.

71. Yew WW, Kwan SYL, Wong PC et al. Ofloxacin and imipenem in the treatment of Mycobacterium fortuitum and Mycobacterium chelonae lung infections. Tubercle 1990;71:131-3.

72. Yew WW, Lau KS, Tse WK, et al. Imipenem in the treatment of lung infections due to Mycobacterium fortuitum and Mycobacterium chelonae: further experience. Clin Infect Dis 1992;15:1046-7.

73. Wallace RJ, Tanner D, Brennan PJ, et al. Clinical trial of clarithromycin for cutaneous (disseminated) in- fection due to Mycobacterium chelonae. Ann Intern Med 1993;119:482-6.

74. Wallace RJ. Diagnostic and therapeutic consideration in patients with pulmonary disease due to rapidly growing mycobacteria. Semin Respir Infect 1986; 1:230-3.

75. Gubler JG, Salfinger M, von-Graevenitz A. Pseudoepidemic of non-tuberculous mycobacteria due to a contaminated bronchoscope cleaning machine. Report of an outbreak and review of the literature. Chest 1992;101(5):1245-9.

76. Collins FM. Bactericidal activity of alkaline glutaraldehyde solution against a number of atypical mycobacterial species. J Appl Bacteriol 1986; 61: 247-251. 